\title{
Multi-Objective Optimization of WEDM of Aluminum Hybrid Composites Using AHP and Genetic Algorithm
}

\author{
Amresh Kumar ${ }^{1}$. Neelkanth Grover ${ }^{2} \cdot$ Alakesh Manna $^{3} \cdot$ Raman Kumar $^{4} \cdot$ Jasgurpreet Singh Chohan ${ }^{4}$. \\ Sandeep Singh ${ }^{5}$. Sunpreet Singh ${ }^{6} \cdot$ Catalin Iulian Pruncu ${ }^{7}$
}

Received: 9 March 2021 / Accepted: 14 June 2021 / Published online: 7 July 2021

(c) Crown 2021

\begin{abstract}
Aluminum hybrid composites have the potential to satisfy emerging demands of lightweight materials with enhanced mechanical properties and lower manufacturing costs. There is an inclusion of reinforcing materials with variable concentrations for the preparation of hybrid metal matrix composites to attain customized properties. Hence, it is obligatory to investigate the impact of different machining conditions for the selection of optimum parameter settings for aluminum-based hybrid metal matrix composite material. The present study aims to identify the optimum machining parameters during wire electrical discharge machining of samples prepared with graphite, ferrous oxide, and silicon carbide. In the present research work, five different process parameters and three response parameters such as material removal rate, surface roughness, and spark Gap are considered for process optimization. Energy-dispersive spectroscopy and scanning electron microscopy analysis reported the manifestation of the recast layer. Analytical hierarchy process and genetic algorithm have been successfully implemented to identify the best machining conditions for hybrid composites.
\end{abstract}

Keywords Wire electrical discharge machining $\cdot$ Optimization $\cdot$ Analytical hierarchy process $\cdot$ Genetic algorithm $\cdot$ Metal matrix composites

\section{Abbreviations}

$\mathrm{Al} \quad$ Aluminum

MMC Metal matrix composites

Al-MMC Aluminum metal matrix composites

WEDM Wire electrical discharge machining
Gr Graphite

$\mathrm{Fe}_{2} \mathrm{O}_{3} \quad$ Ferrous oxide

$\mathrm{SiC} \quad$ Silicon carbide

AHP Analytical hierarchy process

GA Genetic algorithm
Catalin Iulian Pruncu

Catalin.pruncu@strath.ac.uk

Amresh Kumar

amresh.panjla@gmail.com

Neelkanth Grover

neelkanthgrover@rediffmail.com

Alakesh Manna

kgpmanna@rediffmail.com

Raman Kumar

ramankakkar@gmail.com

Jasgurpreet Singh Chohan

jaskhera@gmail.com

Sandeep Singh

drsandeep1786@gmail.com

Sunpreet Singh

Snprt.singh@gmail.com
1 Department of Mechanical Engineering, Chandigarh Engineering College, Landran, Punjab, India

2 Department of Mechanical Engineering, IKG-PTU Campus, Kapurthala, Punjab, India

3 Department of Mechanical Engineering, Punjab Engineering College, Chandigarh, India

4 Department of Mechanical Engineering, Chandigarh University, Mohali, Punjab, India

5 Department of Civil Engineering, Chandigarh University, Mohali, Punjab, India

6 Department of Mechanical Engineering, National University of Singapore, Singapore, Singapore

7 Design, Manufacturing \& Engineering Management, University of Strathclyde, Glasgow, Scotland, UK 


$\begin{array}{ll}\text { SEM } & \text { Scanning electron microscope } \\ \text { EDS } & \text { Energy-dispersive X-ray spectroscopy } \\ \text { DOE } & \text { Design of experiments } \\ \text { MRR } & \text { Material removal rate }\left(\mathrm{mm}^{3} / \mathrm{min}\right) \\ \mathrm{SR} & \text { Surface roughness }(\mu \mathrm{m}) \\ \mathrm{SG} & \text { Spark gap }(\mathrm{mm}) \\ \mathrm{Ip} & \text { Pulse peak current }(\mathrm{A}) \\ \text { Ton } & \text { Pulse-on-time }(\mu \mathrm{s}) \\ \text { Toff } & \text { Pulse-off-time }(\mu \mathrm{s}) \\ \mathrm{WF} & \text { Wire feed rate }(\mathrm{m} / \text { min.) } \\ \mathrm{WT} & \text { Wire tension }(\mathrm{G}) \\ \mathrm{SV} & \text { Spark gap-set voltage }(\mathrm{V}) \\ \mathrm{Ra} & \text { Average Surface Roughness }(\mu \mathrm{m}) \\ \mathrm{SN} \text { ratio } & \text { Signal-to-noise ratio } \\ \mathrm{W}_{\mathrm{g}} & \text { Gap width }(\mu \mathrm{m}) \\ \mathrm{B} & \text { Width of cut }(\mu \mathrm{m}) \\ \mathrm{D} & \text { Diameter of wire electrode }(\mu \mathrm{m}) \\ \mathrm{C}_{\mathrm{m}} & \text { Machining speed (mm/min) } \\ \mathrm{H} & \text { Height of workpiece }(\mathrm{mm}) \\ \mathrm{dB} & \text { Decibels } \\ r_{i j} & \text { Normalized matrix } \\ a_{i j} & \text { Decision matrix } \\ n & \text { Number of entries } \\ V_{i} & \text { Statistical variance } \\ W_{i} & \text { Objective weight } \\ \mathrm{MRR}_{\mathrm{MAX}} & \text { Maximization of material removal rate } \\ \mathrm{SR}_{\mathrm{MIN}} & \text { Minimization of surface roughness } \\ \mathrm{SG}_{\mathrm{MIN}} & \text { Minimization of spark gap } \\ \mathrm{Z}_{\mathrm{MIN}} & \text { Multi-objective function minimization } \\ & \end{array}$

\section{Introduction}

MMC materials are an exciting alternative to counter the growing demand for lighter materials as they exhibit high strength specifically for dynamic structures [1]. Due to customized properties, these materials have been consistently used for armored vehicles, driveshafts, turbine rotors, lightweight bicycle frames, and engine components [2]. Some of the major automobile manufacturers such as Honda, General Motors, Toyota, and Nissan are using MMCs for production of engine blocks, piston rings, connecting rods, calipers, liners, etc. [3]. The performance advantages of MMCs are their tailored thermo-physical properties that include low density, high fatigue strength, good thermal conductivity, and wear resistance [4]. Al, in alloy form, is the best-sought matrix for the fabrication of MMCs due to the reason that these are economical and possess good compatibility with a wide range of ceramic reinforcements. The mechanical properties of Al-MMC can be tailored by selectively introducing ceramic particulates in the matrix phase, i.e., $\mathrm{Al}$ alloy. AlMMCs are specifically used for multichip electronic modules and Printer Circuit Board heat sinks by Alcoa Innometalx and Lanxide, respectively [3]. The materials such as $\mathrm{Al}_{2} \mathrm{O}_{3}$, $\mathrm{SiC}, \mathrm{Gr}, \mathrm{SiO}_{2}, \mathrm{~B}, \mathrm{~B}_{4} \mathrm{C}, \mathrm{BN}$, and $\mathrm{AlN}$ are among the choices to reinforce the metal/alloy matrix [5]. These materials are finding myriad applications in the aerospace, defense, electronic packaging, and automotive industry [6]. MMCs can be fabricated through a wide range of manufacturing methods. These include liquid metallurgy and powder metallurgy, deposition of matrix vapor phase [7, 8]. Processing through the liquid metallurgy route has proven to be economical [9]. Further, stir casting is a comparatively simpler and economical choice to produce MMC materials in bulk. In such methods, the solidification rate of the molten alloy, which is added with reinforcement material, influences the microstructures of the cast MMC. The hybrid MMCs are gaining popularity owing to better property combinations offered by multiple reinforcements being incorporated in the matrix phase [10]. Reportedly, many researchers have taken a keen interest in the processing of composites made of combinations of alloys/metals and reinforcing materials. Interestingly, the simultaneous addition of soft reinforcements such as graphite improves the wear behavior of the composite materials which were made harder by the addition of $\mathrm{SiC}$ as a ceramic reinforcement [11].

Having witnessed the vulnerability of the conventional tools in the machining of MMCs, the researchers are relying on non-conventional machining methods. One of such prospectuses, i.e., electrical discharge machining technology, has caught decent attention from manufacturing engineers owing to its proven potential in cutting intricate shapes in dies, punches, and molds made of materials known for superior mechanical properties [12,13]. Over the years, the Electrical Discharge Machining process has become a key machining intervention to cut electrically conductive materials without worrying about their range. WEDM has taken greater attention of researchers in the last decade due to the supply of soft computing techniques such as genetic algorithm, fuzzy logics and artificial neural network [14]. Besides advanced algorithms, conventional optimization techniques such as Taguchi and principal component analysis have been widely adopted as modeling methods [15]. The objective function in the Electrical Discharge Machining and WEDM processes can be defined in many ways to offer solutions to multi-response optimization problems.

Rajyalakshmi and Ramaiah [16] applied the Taguchi and grey relational analysis during an experimental study on Inconel 825 using WEDM process. The study was focused to improve the MRR, SR, and SG. The experiment was conducted using $\mathrm{L}_{36}\left(2^{1} \times 3^{7}\right)$ orthogonal array design based upon Taguchi's method and finally, the response graph plots for grey relational analysis were produced. Theory of grey relational analysis convincingly overcomes the shortcomings of conventional statistical methods and only requires limited information to predict the behavior of uncertain and complex 
systems. Fard et al. [17] investigated dry WEDM using integrated Adaptive Neuro-Fuzzy Inference System models with the Artificial Bee Colony algorithm. So, researchers assigned weights to different responses to meet different machining requirements. Krishna and Rao [18] applied a harmony search algorithm to simultaneous optimization of performance measures such as wire wear and kerf width and successfully proposed an optimal set of machining control parameters.

In an attempt to investigate the mechanical strength, hardness, and wear resistance of aluminum reinforced with silicon carbide and tungsten, Fenghong et al. [19] used the stir casting technique for sample preparation. Improvement in mechanical strength, hardness, and wear resistance was experienced due to uniform distribution of reinforcements. Palanisamy et al. [20] studied the impact of three process parameters of EDM on surface finish, tool wear, and material removal rate while machining of stir-casted Al-MMCs. Grey relation analysis technique was implemented to identify optimum conditions, and maximum impact of discharge current was observed. In a recent study [21], composites were prepared using AA6061 as matrix material and SIC as reinforcement along with jute ash to highlight agriculture waste management. It was observed that tensile strength, wear resistance, and hardness of stir-casted samples were increased due to proper dispersion of reinforcements. Moreover, the presence of $\mathrm{SiC}$ enhanced the wear resistance and hardness.

Yadav et al. [22] reported an improvement in bonding strength of matrix material (Al) reinforced with $\mathrm{SiC}$ and titanium diboride. Stir casting has been used to prepare test samples of $\mathrm{Al}$ reinforced by tungsten carbide; findings reveal that there was an increase of $62 \%$ and $6 \%$ in tensile strength and hardness respectively [23]. On the other hand, the flexural strain was reduced with an increase in molybdenum disulfide powder in AA6061-T6 [24]. In another study, the doping of graphite manifested better wear resistance as compared to than molybdenum disulfide particles-based composite for the selected parameters at a normal environment. Moreover, under all conditions, the wear rate increases with an applied load and sliding distance [25]. Kumar et al. [26] predicted the optimum conditions for maximized wear resistance and tensile strength of $\mathrm{Al}$ reinforced with $\mathrm{SiC}$ particles. It was found that $15 \mathrm{~s}$ dispersion time with $45^{\circ}$ blade angle and stirring speed of $250 \mathrm{rpm}$ yielded the best results.

Computational fluid dynamics was used to predict the best blade design based on hardness and compressive strength of stir-casted aluminum composites [27]. Researchers [28] have also investigated the vortex pressure through computational fluid dynamics during composite preparation as it significantly affects particle distribution. The flow pattern of reinforcements was visualized and optimized using the Taguchi DOE method. It was deduced that holding time of ten minutes and $45^{\circ}$ stirrer blade angle resulted in maximum homogeneity. Finite element modeling studies have been performed to compare the tensile strength during experimentation and simulation [29]. The best results were found with $15 \%$ reinforcement of $\mathrm{SiC}$, and simulation results were supported by experimental data.

Literature survey and recent studies [30] reveal that some experimental work has been conducted and optimization tools are implemented to optimize surface finish, material removal rate, mechanical and morphological properties of stir-casted Al-MMCs during EDM. The practical limitations of these studies are the lack of advanced optimization tools such as AHP and GA which solve complex problems with multiple and conflicting responses. There is a lack of acceptable and of adequate analytical models to predict the machine response characteristics due to the stochastic nature of WEDM and the presence of the reinforcements in the host matrix material adds more complexity. It necessitates experimental investigations of WEDM using samples of aluminum-based MMC, and further developing predictive regression models. Because many machining parameters influence the process and uncertain nature of these processes, realizing the best performance is a challenge, which needs to apply research on this area. At the production stage, manufacturing industries use such optimization tools for multi-objective optimization which yields maximized output. For meeting these challenges, the present work is focused on multi-objective optimization wherein weights have been assigned to various performance measures to cater to the need of various sectors. The outcome of the study presented in this research work will be able to give new guidelines to researchers and practitioners to understand the influence of various parameters on responses for machining $\mathrm{Al} /\left(\mathrm{SiC}_{\mathrm{p}}+\mathrm{Gr}_{\mathrm{P}}+\mathrm{Fe}_{2} \mathrm{O}_{3 \mathrm{p}}\right)$ hybrid MMC.

\section{Materials and Methods}

The aluminum hybrid composite sample used for the present study has been casted by preheating SIC), $\mathrm{Gr}$ and $\mathrm{Fe}_{2} \mathrm{O}_{3}$ followed by mold cavity preparation. Afterward, the aluminum was stir-casted using an electric motor for uniform and vortex flow.

Electronica Sprincut-734 made WEDM was used for experiments. The MRR and average SR were measured during WEDM operations. The WEDM machine tool was programmed to cut the workpiece into a size of $5 \mathrm{~mm} \times 5 \mathrm{~mm} \times 12 \mathrm{~mm}$ in each machining operation. The machined surface roughness height was measured at three different positions, and the mean values were taken for analyzing the machined surface quality using surface roughness heights measuring instrument (supplied by Surfcom 130A, Zeiss, Japan). The SR is based upon roughness average (Ra), 
which is desired to be minimum, hence considered as output for the present study. An evaluation length of $4 \mathrm{~mm}$ was used to determine SR after each experiment. The average cutting speed data $(\mathrm{mm} / \mathrm{min})$ are measured upon with reference to the original length of cutting operation for each trial. The width of cuts $(\mathrm{B}, \mathrm{mm})$ was evaluated using Digimatic Caliper Mitutoyo, Japan. The relation as per Eq. (1) has got in use to determine the spark gap width $(\mathrm{Wg}, \mu \mathrm{m})$ for each experiment [30].

$2 W_{g}+D=B$

MRR for each experiment performed is based upon Eq. (2) [30].

$\operatorname{MRR}=\left(C_{m} \cdot B \cdot H\right) \mathrm{mm}^{3} / \min$

Taguchi DOE technique is used for current experimentation as it has got an edge with the potential of considering multiple factors at once and determining the optimal parameters with lesser experimental trials than the conventional DOE approach. As per this approach, the $\mathrm{L}_{27}$ orthogonal array was selected for performing the experimental investigation. According to a chosen orthogonal array, only 27 experiments are required to be performed to study the entire control parameter space using the $\mathrm{L}_{27}$ orthogonal array. Each control parameter is assigned to a column, and 27 control parameter combinations are needed.

Table 1 describes the WEDM parameters considered for experiments along with their chosen levels. Further, 27 combinations involving each factor as well as their levels in equal ratio to retain the orthogonality of the design of experiments were formulated [19]. The flowchart of the present methodology is shown in Fig. 1.

The SN ratio is defined in mathematical form for higherthe-better (i.e., maximization of output, example: MRR) and shown as Eq. (3) [30]:

SN Ratio $\eta=-10 \log _{10}\left\lfloor 1 / n \sum_{i=1}^{n} 1 / y_{i}^{2}\right\rfloor$

and for lower-the-better (i.e., minimization of output, example: SR) and shown as Eq. (4) [30]:
SN Ratio $\quad \eta=-10 \log _{10}\left\lfloor 1 / n \sum_{i=1}^{n} y_{i}^{2}\right\rfloor$

Figure 2a plots the EDS spectra of a machined sample which indicates the presence of carbon, zinc, silicon, magnesium, and oxygen, while aluminum has a major concentration at $1.5 \mathrm{keV}$. The presence of oxygen indicates the deionization of dielectric fluid at elevated temperatures which occurs due to high pulse-on time. This phenomenon is confirmed by the porosity manifested in the machined surface as visualized in the SEM micrograph in Fig. 2b. Some cracks can be noticed on the machined surface owing to the high temperature generated from the recast layer during WEDM machining. However, most areas of the machined surface are free from cracks owing to moderate tensile residual stress in the recast layer. Figure $2 \mathrm{c}$ shows the elemental concentration retrieved from SEDS testing.

\section{Results and Discussion}

In the present work, the effect of six independent variables viz. Ip, $\mathrm{T}_{\mathrm{on}}$, Toff, WF, WT, SV on three different dependent variables viz. MRR, SR and SG is investigated using regression tools, AHP, and GA.

The SN ratios of MRR, SR, and SG in all the 27 experimental runs have been calculated using Minitab 19 analytical tool and are shown in Table 2. The specimen prepared during experimentation is displayed in Fig. 3.

As per 3D response surface plots, the interaction effects of Ip, Ton, Toff, WF, WT, SV on MRR are recovered. As per the WEDM process, the process of melt removal occurs on the machined surface in the form of craters. The MRR value starts increasing with an increase in the peak current but instead decreases with the pulse peak current rising further, as shown in Fig. 4a. The simultaneous effect of Ton and WF on MRR is shown in Fig. 4b. In the machining zone, the rise in pulse peak current provides greater electrical discharge energy, fostering deeper craters on the machined surface, leading to higher MRR. But deeper craters minimize the energy density of the discharge on the electrical discharge
Table 1 Levels of variables used during experimentation

\begin{tabular}{lllllll}
\hline S. No & Input parameters & Notation & \multicolumn{2}{l}{ Level } & \multirow{2}{*}{ Unit } \\
\cline { 5 - 6 } & & & 1 & 2 & 3 & \\
\hline 1 & Pulse peak current (Ip) & A & 80 & 100 & 120 & A \\
2 & Pulse-on-time (Ton) & B & 0.5 & 0.8 & 1.1 & $\mu \mathrm{s}$ \\
3 & Pulse-off-time (Toff) & C & 20 & 16 & 12 & $\mu s$ \\
4 & Wire feed rate (WF) & D & 5 & 7 & 9 & $\mathrm{~m} / \mathrm{min}$ \\
5 & Wire tension (WT) & E & 850 & 1000 & 1200 & $\mathrm{G}$ \\
6 & Spark gap-set voltage (SV) & F & 25 & 30 & 35 & V \\
\hline
\end{tabular}




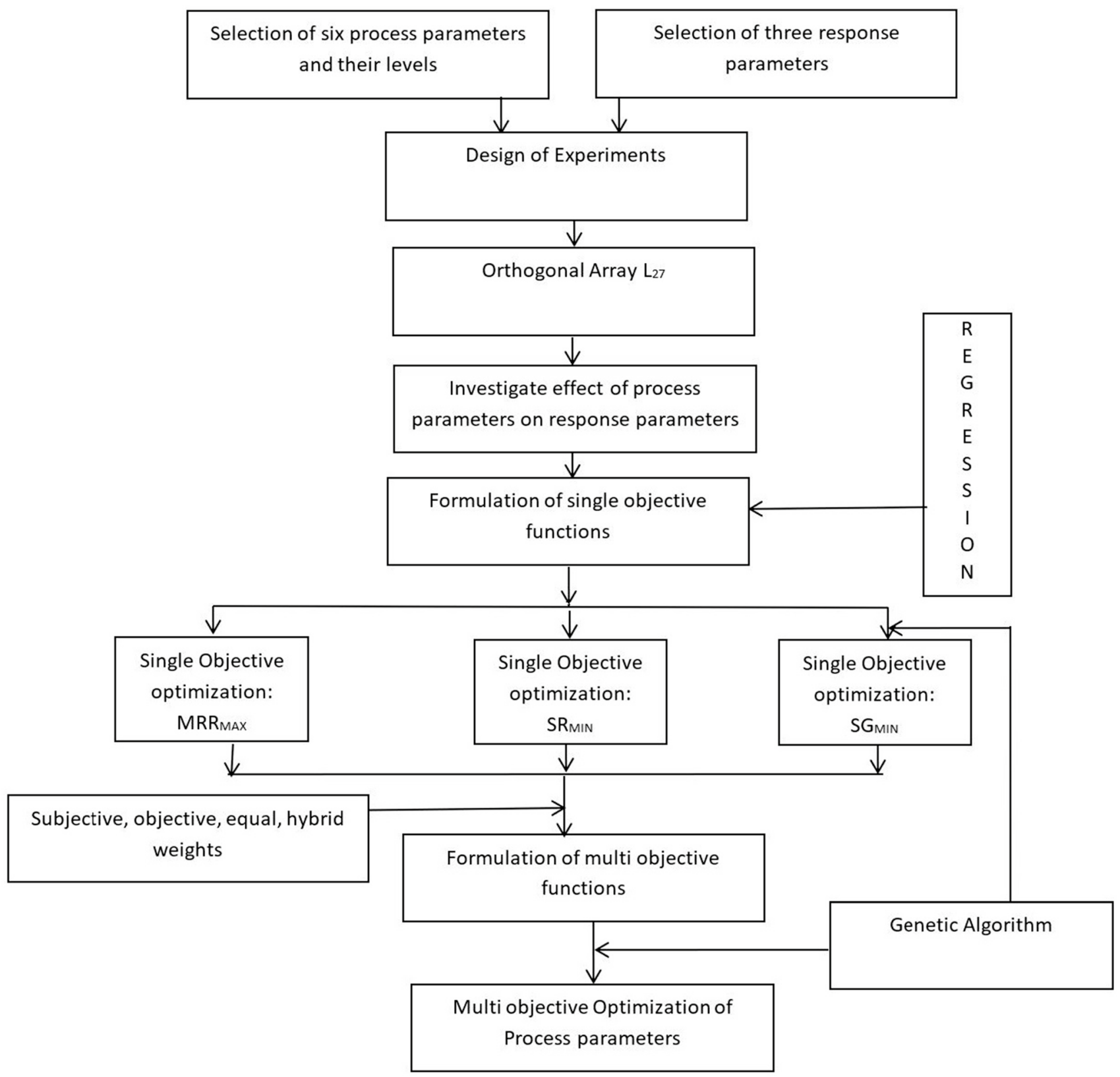

Fig. 1 Process flowchart for experimentation

spot and thus decrease the MRR. With the decrease in pulseoff time, it is shown that the values of MRR continue to increase disingenuously. The frequency of discharges over a machining period has been correlated with this case. The high number of discharges within a specific interval of time has a tendency to produce more melt and hence more MRR. The presence of ceramic reinforcements can diffuse a significant amount of thermal energy which can decrease the MRR at a low-level setting of pulse-on-time. However, extended pulse duration renders a sharp spike in thermal energy and hence causes more erosion of the workpiece. The increase in wire feed had a positive impact on MRR.
Figure 5a plots the effect of Ton and WF on MRR. The increase in WF induced a slight increase in surface roughness, and maximum surface roughness of $1.6 \mu \mathrm{m}$ was achieved at $9 \mathrm{~m} / \mathrm{min}$. Whereas the increase in Ton increases the roughness to $1.5 \mu \mathrm{m}$ up to $0.85 \mu \mathrm{s}$, it remains constant with further increase in Ton. The abrupt initial increase in roughness of materials occurs due to higher Ton, the spark time is elongated which erodes higher material. The phenomenon of pit formation is observed at higher Ton conditions which decrease the surface clarity. However, this phenomenon led to a higher material removal rate as discussed. Figure $5 b$ shows initially the SR increase with an increase 


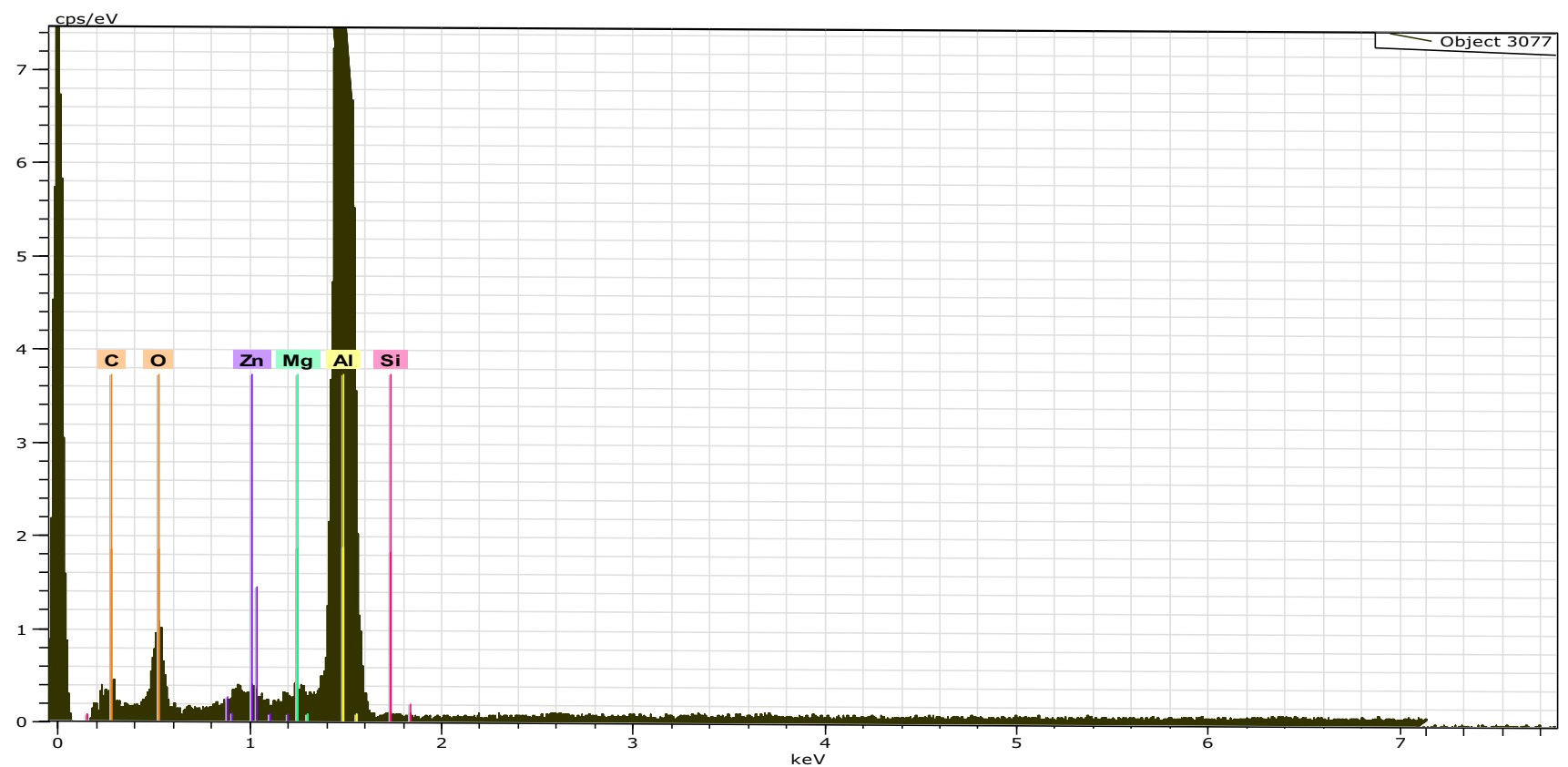

(a)

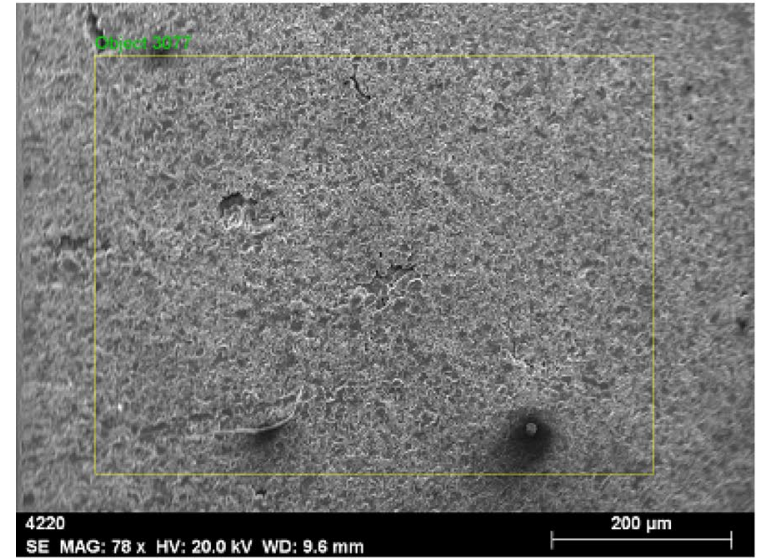

(b)

\begin{tabular}{|c|c|c|c|c|c|c|}
\hline E1 & AN & Series & $\begin{array}{c}\text { unn. } \\
\text { wt. \% }\end{array}$ & $\begin{array}{c}\text { C norm. } \\
\text { wt. \% }\end{array}$ & $\begin{array}{c}\text { C Atom. } \\
\text { at. } \%\end{array}$ & $\begin{array}{c}\text { C Error } \\
(\%)\end{array}$ \\
\hline $\mathrm{Al}$ & 13 & K-Series & 92.56 & 65.67 & 51.58 & 4.5 \\
\hline $\mathrm{O}$ & 8 & K-Series & 28.21 & 20.01 & 26.51 & 5.5 \\
\hline $\mathrm{C}$ & 6 & K-Series & 15.98 & 11.34 & 20.01 & 3.7 \\
\hline $\mathrm{Mg}$ & 12 & K-Series & 2.04 & 1.45 & 1.26 & 0.2 \\
\hline $\mathrm{Zn}$ & 30 & K-Series & 1.65 & 1.17 & 0.38 & 0.2 \\
\hline $\mathrm{Si}$ & 14 & K-Series & 0.49 & 0.35 & 0.26 & 0.1 \\
\hline \multicolumn{3}{|c|}{ Total } & 140.94 & 100.00 & 100.00 & \\
\hline
\end{tabular}

(c)

Fig. 2 a EDS spectra of the processed specimen b SEM image of surface $\mathbf{c}$ weight percentage of elements

in spark voltage, while after $30 \mathrm{~V}$, the $\mathrm{SR}$ is decreased. The increase in SR at the medium range may be attributed to unstable spark at this level which created non-uniform material removal from the surface leading to asperities. However, the lower and upper range yields good surface finish values due to uniform erosion. On other hand, SR is directly proportional to wire tension. The increased frequency of oscillation of wire results in the deterioration of material surface.

In Fig. 6a, the effects of Toff and Ip on SG are shown. The linear existence of SG variance with a time off pulse was observed. The breakage in pulse slightly increases the gap between tool and workpiece. For all current set values, the SG increases with the decrease in Toff. Higher spark voltage and lower WT combination can be shown to result in lower
SG (see Fig. 6b). The spark voltage and wire tension are the most significant parameters which influence the spark gap.

\section{Multi-Objective Optimization}

As discussed in the previous section, the impact of each parameter on output is different and non-uniform. Moreover, the parameters are interacting with each other, and hence it is difficult to identify optimum conditions for three response parameters. Conventional optimization techniques cannot suggest a single set of parameters for attaining the best values of MRR, SR, and SG for the present context. Hence, there is a need to implement an 
Table 2 SN ratios for MRR, $\mathrm{SR}$, and SG for each experiment

\begin{tabular}{|c|c|c|c|c|c|c|c|c|c|}
\hline \multirow[t]{2}{*}{$\begin{array}{l}\text { Exp } \\
\text { No }\end{array}$} & \multicolumn{6}{|c|}{ Control parameters } & \multicolumn{3}{|l|}{$\begin{array}{l}\text { S/N ratios } \\
\text { (dB) }\end{array}$} \\
\hline & $\begin{array}{l}\mathrm{A} \\
\left(\mathrm{I}_{\mathrm{p}}\right)\end{array}$ & $\begin{array}{l}\mathrm{B} \\
\left(\mathrm{T}_{\mathrm{on}}\right)\end{array}$ & $\begin{array}{l}\mathrm{C} \\
\left(\mathrm{T}_{\text {off }}\right)\end{array}$ & $\begin{array}{l}\mathrm{D} \\
\left(\mathrm{W}_{\mathrm{F}}\right)\end{array}$ & $\begin{array}{l}\mathrm{E} \\
\left(\mathrm{W}_{\mathrm{T}}\right)\end{array}$ & $\begin{array}{l}\mathrm{F} \\
(\mathrm{SV})\end{array}$ & MRR & SR & SG \\
\hline 1 & 80 & 0.5 & 20 & 5 & 850 & 25 & 14.3201 & 0.19322 & 35.8097 \\
\hline 2 & 80 & 0.5 & 20 & 5 & 1000 & 30 & 14.1514 & -1.82630 & 35.6503 \\
\hline 3 & 80 & 0.5 & 20 & 5 & 1200 & 35 & 14.9015 & -3.26323 & 35.3401 \\
\hline 4 & 80 & 0.8 & 16 & 7 & 850 & 25 & 16.3381 & -0.83575 & 34.5632 \\
\hline 5 & 80 & 0.8 & 16 & 7 & 1000 & 30 & 18.7604 & -1.83334 & 33.4733 \\
\hline 6 & 80 & 0.8 & 16 & 7 & 1200 & 35 & 18.1911 & -1.91036 & 33.2309 \\
\hline 7 & 80 & 1.1 & 12 & 9 & 850 & 25 & 19.4162 & -1.01069 & 32.7278 \\
\hline 8 & 80 & 1.1 & 12 & 9 & 1000 & 30 & 19.6905 & -4.38645 & 32.6157 \\
\hline 9 & 80 & 1.1 & 12 & 9 & 1200 & 35 & 19.2663 & -4.88059 & 32.4685 \\
\hline 10 & 100 & 0.5 & 16 & 9 & 850 & 30 & 17.5704 & -3.22736 & 33.6387 \\
\hline 11 & 100 & 0.5 & 16 & 9 & 1000 & 35 & 17.7050 & -3.76732 & 33.7649 \\
\hline 12 & 100 & 0.5 & 16 & 9 & 1200 & 25 & 17.5716 & -5.67959 & 33.1122 \\
\hline 13 & 100 & 0.8 & 12 & 5 & 850 & 30 & 21.1761 & -2.54210 & 32.6902 \\
\hline 14 & 100 & 0.8 & 12 & 5 & 1000 & 35 & 21.7343 & -3.33452 & 32.2879 \\
\hline 15 & 100 & 0.8 & 12 & 5 & 1200 & 25 & 20.9299 & -5.50162 & 32.7278 \\
\hline 16 & 100 & 1.1 & 20 & 7 & 850 & 30 & 19.6155 & -3.26323 & 32.0065 \\
\hline 17 & 100 & 1.1 & 20 & 7 & 1000 & 35 & 19.1808 & -2.05553 & 32.2879 \\
\hline 18 & 100 & 1.1 & 20 & 7 & 1200 & 25 & 19.0578 & -3.18533 & 32.7278 \\
\hline 19 & 120 & 0.5 & 12 & 7 & 850 & 35 & 18.6900 & -2.57445 & 33.1122 \\
\hline 20 & 120 & 0.5 & 12 & 7 & 1000 & 25 & 17.7298 & -3.78419 & 32.5786 \\
\hline 21 & 120 & 0.5 & 12 & 7 & 1200 & 30 & 17.5012 & -3.96214 & 32.4320 \\
\hline 22 & 120 & 0.8 & 20 & 9 & 850 & 35 & 18.6566 & -0.98436 & 32.3597 \\
\hline 23 & 120 & 0.8 & 20 & 9 & 1000 & 25 & 18.4856 & -2.58090 & 32.1110 \\
\hline 24 & 120 & 0.8 & 20 & 9 & 1200 & 30 & 18.8461 & -4.43350 & 32.4685 \\
\hline 25 & 120 & 1.1 & 16 & 5 & 850 & 35 & 19.7157 & -3.11886 & 32.0065 \\
\hline 26 & 120 & 1.1 & 16 & 5 & 1000 & 25 & 20.1439 & -4.36546 & 32.1110 \\
\hline 27 & 120 & 1.1 & 16 & 5 & 1200 & 30 & 19.6155 & -3.14914 & 31.9376 \\
\hline
\end{tabular}

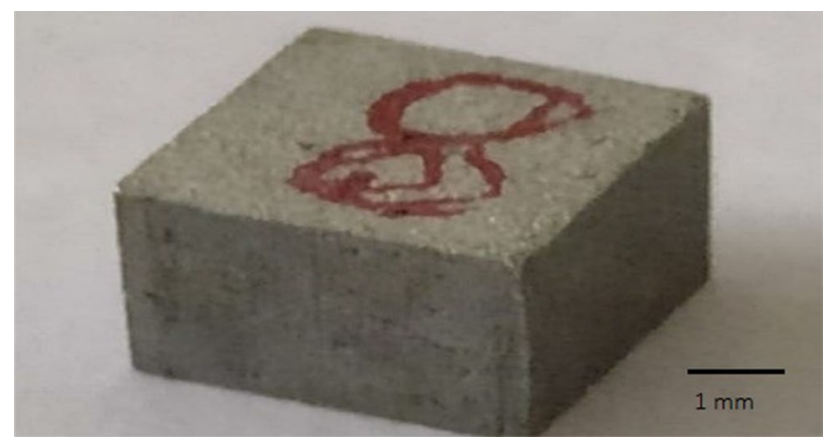

Fig. 3 Specimen prepared after machining

advanced optimization technique that may suggest the optimum parametric settings. In the present study, regression analysis is implemented followed by GA and AHP.

\subsection{Regression Analysis}

The regression method is applied to investigate the effect of input on output. SPSS software is used to apply the regression method. The present work is focused on three response parameters; therefore, four single objective equations are formulated with the help of the regression method. In the manufacturing environment, numerous variables influence the output parameters. The mathematical model defines a relationship between independent and response parameters as shown in Eq. 5 [31].

$Y=\beta_{0}+\sum_{i=1}^{n} \beta_{i} \times C_{i}+\sum_{i=1}^{n} \beta_{\mathrm{ii}} \times C_{i}^{2}+\sum_{i=1}^{n} \beta_{\mathrm{ij}} \times C_{i} C_{j}$

For six variables, Eq. 5 can be written as shown in Eq. 6, where $\mathrm{C}_{1}, \mathrm{C}_{2}, \mathrm{C}_{3}, \mathrm{C}_{4}, \mathrm{C}_{5}, \mathrm{C}_{6}$ are the process parameters and $\mathrm{Y}$ denotes the response parameters [31]. 

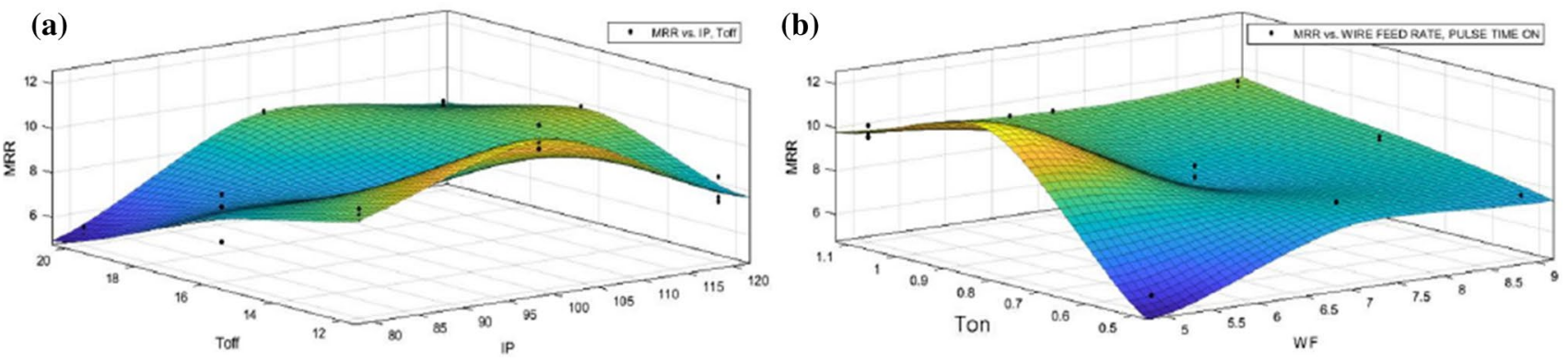

Fig. 4 a Effect of Ip and Toff on MRR b Effect of Ip and WF on MRR
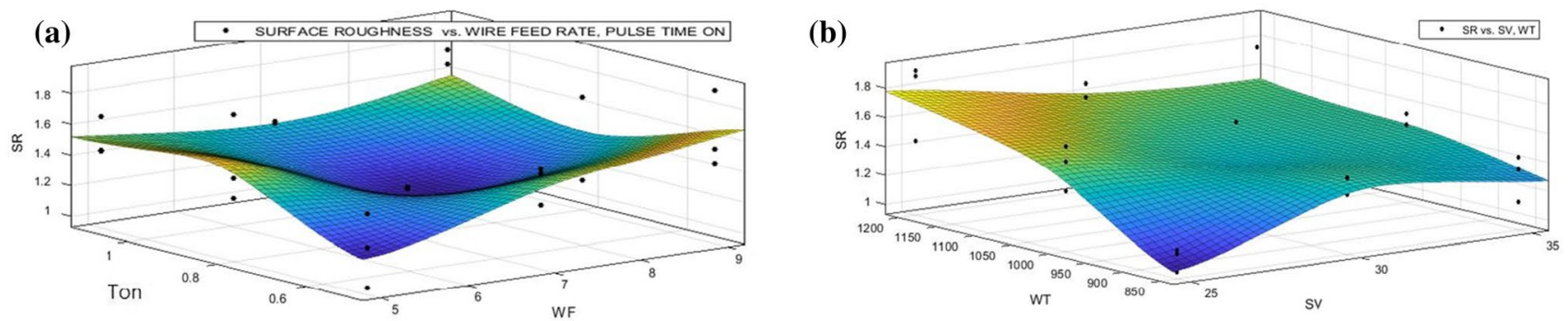

Fig. 5 a Effect of Ton and WF on SR b Effect of WT and SV on SR
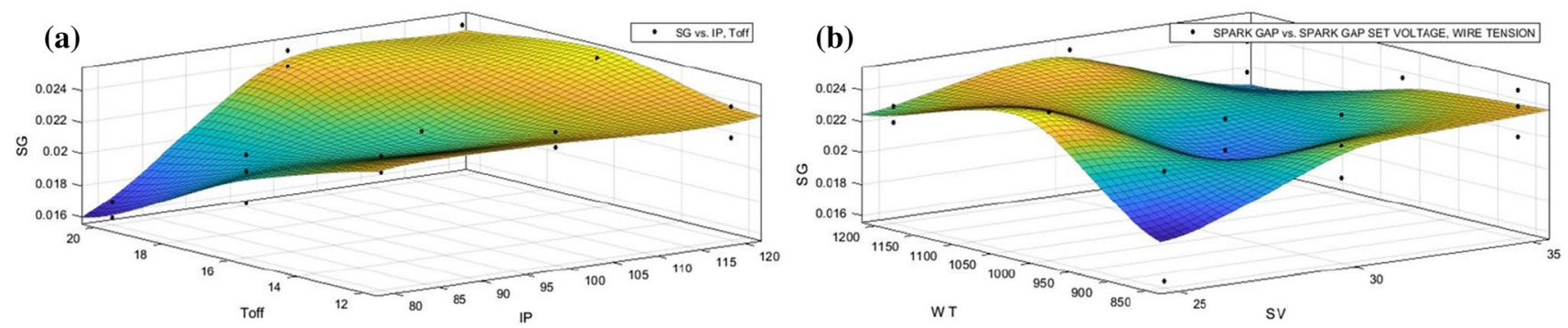

Fig. 6 a Effect of Toff and Ip on SG b Effect of SV and WT on SG

$$
\begin{aligned}
Y & =\beta_{0}+\beta_{1} C_{1}+\beta_{2} C_{2}+\beta_{3} C_{3}+\beta_{4} C_{4} \\
& +\beta_{5} C_{5}+\beta_{6} C_{6}+\beta_{7} C_{1} \times C_{2}
\end{aligned}
$$

In the present context, there are six input variables of the WEDM process, whereas MRR, SR, and SG are output parameters. Three Eqs. (7, 8, and 9) are developed, one for each output, using regression methods, where maximization of MRR and minimization of SR and SG are objectives respectively.

$$
\begin{aligned}
\operatorname{MRR}_{\mathrm{MAX}}= & -94+0.53 A-35.1 B+1.74 C+4.9 D+0.148 E+3.98 F-0.00233 A \times A+26.6 B \times B \\
& -0.056 C \times C+0.0999 D \times D-0.000036 E \times E-0.0431 F \times F-0.000486 A \times E-0.0261 A \times F-0.0324 B \times E \\
& +2.28 B \times F+0.00240 C \times E-0.116 C \times F-0.0111 D \times E-0.536 D \times F+0.00581 A \times D \times F-0.130 B \times D \times F \\
& +0.000217 D \times E \times F
\end{aligned}
$$




$$
\begin{aligned}
\mathrm{SR}_{\mathrm{MIN}}= & -91.4+0.615 A-5.5 B+2.69 C+4.14 D+0.0937 E+0.430 F-0.00307 A \times A+3.95 B \times B \\
& -0.0828 C \times C+0.0282 D \times D-0.000024 E \times E-0.0252 F \times F-0.000302 A \times E+0.00892 A \times F \\
& -0.01836 B \times E+0.215 B \times F+0.001266 C \times E-0.0464 C \times F-0.00721 D \times E-0.159 D \times F \\
& +0.00043 A \times D \times F+0.0572 B \times D \times F+0.000161 D \times E \times F
\end{aligned}
$$

$$
\begin{aligned}
\mathrm{SG}_{\mathrm{MIN}}= & 0.088-0.000749 A-0.0247 B-0.00456 C-0.00143 D-0.000067 E+0.00405 F \\
& +0.000006 A \times A+0.0219 B \times B+0.000156 C \times C-0.000083 D \times D+0.000000 E \times E+0.000006 F \times F \\
& +0.000000 A \times E-0.000048 A \times F+0.000026 B \times E+0.00112 B \times F-0.000003 C \times E+0.000059 C \times F \\
& +0.000009 D \times E-0.000263 D \times F+0.000004 A \times D \times F-0.000267 B \times D \times F-0.000000 D \times E \times F
\end{aligned}
$$

Surface plots showed that there is a non-uniform impact of each process parameter on MRR, SR, and SG of parts processed through WEDM process. The optimum parametric settings of MRR would adversely impact the SR and SG and vice versa. Hence, there is a need to identify a single set of parameters that would yield satisfactory results in terms of MRR, SR, and SG. This multi-objective problem of WEDM can be solved by implementing AHP and GA. Conventionally, the weighted sum approach, distance function method, min-max, and Taguchi techniques are used for solving multi-objective problems. However, the accuracy of these methods depends upon the knowledge of the expert who decides the ranking and relative importance of objective functions. Discontinuity of objective function is another limitation of these techniques. Hence, the combination of AHP and GA is used in the present study of multi-objective problems [32]. GA is a robust technique that eliminates the requirement of gradient information and inherent parallelism for locating design space. The primary aim is to determine a single combination of WEDM process parameters within the constraints which would simultaneously maximize the MRR and minimize the SR and SG. Initially, three equations for each objective function (MRR, SR, and SG) are converted into a single equation as a multi-objective function as shown in Eq. 13.

\subsection{Implementation of AHP}

The simple method to convert single objective equations into a multi-objective equation is a weighted sum method and the same technique is adopted in the present work. The weightage is assigned to single objective equations to formulate a multi-objective equation. In this research work, a hybrid methodology is adopted to assign the weightage to objective functions. The AHP and statistical variance are used to assign subjective weights and objective weights respectively [33]. Afterward, AHP is implemented to assign different types of objective weights to each response and displayed in Table 3.

AHP is the most commonly used multi-criteria decisionmaking tool to find the subjective priority of attributes. The nine-point Satty's scale was used to develop a pairwise comparison between response parameters. The expert's opinions were taken to formulate the pairwise comparison matrix [32].

Objectives weights of attributes can be determined using the statistical variance concept. The steps involved in finding the values of objective weights are mentioned below:

Step 1 Decision matrix: The values of attributes in a tabular form.

Step 2 Normalized matrix: The normalized matrix can be developed using Eq. 10 [33].

$r_{\mathrm{ij}}=a_{\mathrm{ij}} / \sum_{i}^{n} a_{\mathrm{ij}}$

Step 3 Compute the values of statistical Variance: The values of statistical variance are found using Eq. 11 [33]:

Table 3 Subjective weights for AHP

\begin{tabular}{lllll}
\hline & MRR & SR & SG & $\begin{array}{l}\text { Subjec- } \\
\text { tive } \\
\text { weights }\end{array}$ \\
\hline MRR & 1 & $1 / 2$ & 2 & 0.297 \\
SR & 2 & 1 & 3 & 0.54 \\
SG & $1 / 2$ & $1 / 3$ & 1 & 0.163 \\
\hline
\end{tabular}

Table 4 Different objective weights assigned to response parameters

\begin{tabular}{llll}
\hline & MRR & SR & GG \\
\hline AHP Weights & 0.297 & 0.540 & 0.163 \\
Equal weights & 0.333 & 0.333 & 0.333 \\
Objective weights & 0.506 & 0.332 & 0.162 \\
Hybrid weights & 0.381 & 0.405 & 0.214 \\
\hline
\end{tabular}


$V_{i}=\frac{1}{n} \sum_{i=1}^{n}\left\{r_{\mathrm{ij}}-\left(r_{\mathrm{ij}}\right) \text { mean }\right\}^{2}$

Fig. 7 Steps in implementation of genetic algorithm in present study
Step 4 Determine objective weights: The objective weights are computed using Eq. 12 [33].
Define fitness function

$\downarrow$

Generate Initial random population of chromosomes

$\downarrow$

Evaluate fitness for each chromosomes

Selection of parent chromosomes from the population

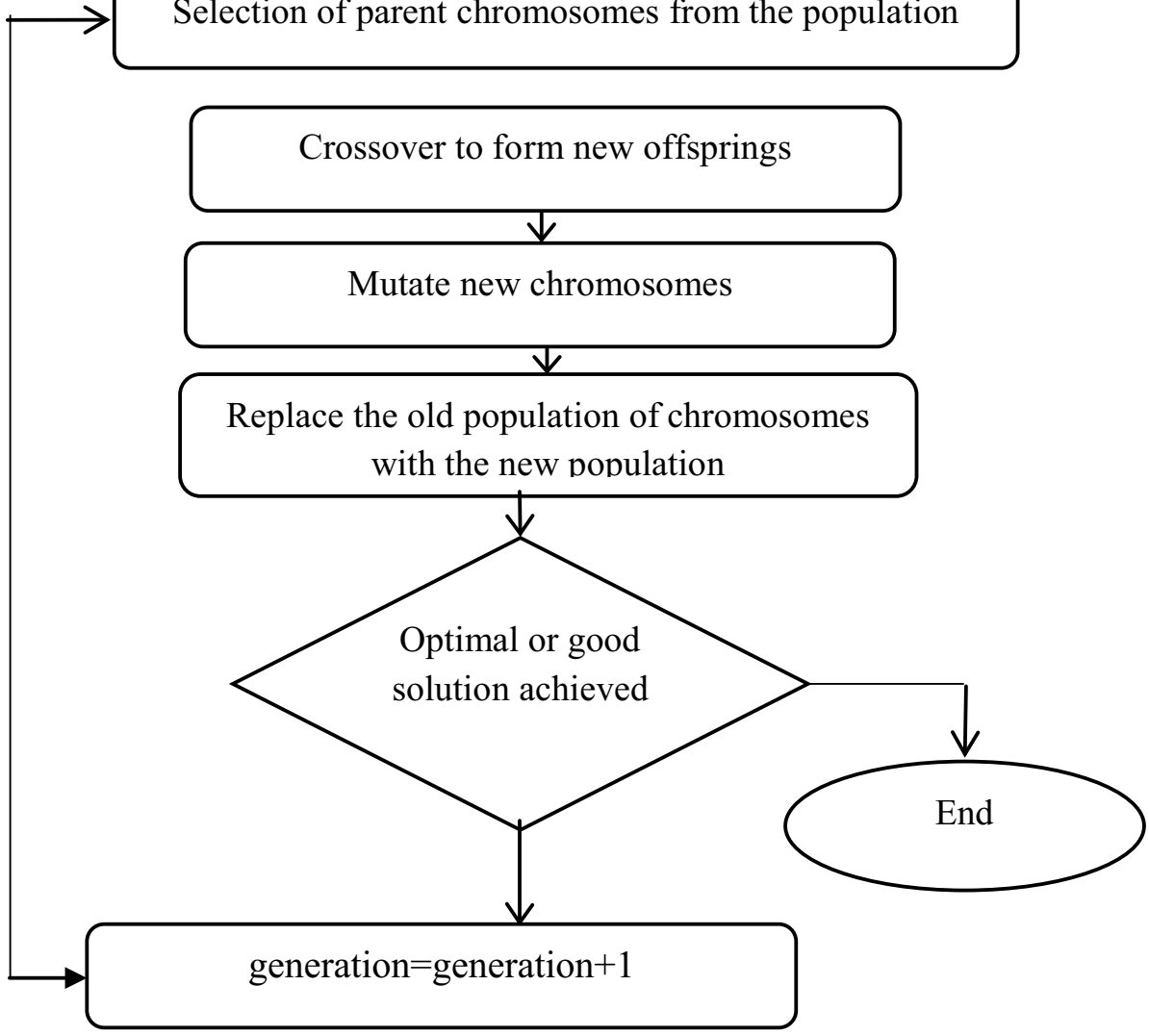

Table 5 Single and multiobjective optimization results

\begin{tabular}{llllllll}
\hline Optimization type & Goal & Ip & Ton & Toff & WF & WT & SV \\
\hline Single objective & MRR $_{\text {MAX }}$ & 80.000 & 0.500 & 12.000 & 5.000 & 850.000 & 35.000 \\
Single objective & SR $_{\text {MIN }}$ & 80.000 & 0.500 & 12.000 & 9.000 & 850.000 & 35.000 \\
Single objective & $\mathrm{SG}_{\mathrm{MIN}}$ & 120.000 & 1.100 & 12.000 & 9.000 & 1200.000 & 25.000 \\
Multi-objective using equal weights & $\mathrm{Z}_{\mathrm{MIN}}$ & 80.000 & 0.500 & 12.000 & 5.000 & 850.000 & 35.000 \\
Multi-objective using AHP weights & $\mathrm{Z}_{\mathrm{MIN}}$ & 80.000 & 0.500 & 12.000 & 5.000 & 850.000 & 35.000 \\
Multi-objective using Objective weights & $\mathrm{Z}_{\mathrm{MIN}}$ & 80.000 & 0.500 & 12.000 & 5.000 & 850.000 & 35.000 \\
Multi-objective using Hybrid weights & $\mathrm{Z}_{\mathrm{MIN}}$ & 80.000 & 0.500 & 12.000 & 5.000 & 850.000 & 35.000 \\
\hline
\end{tabular}



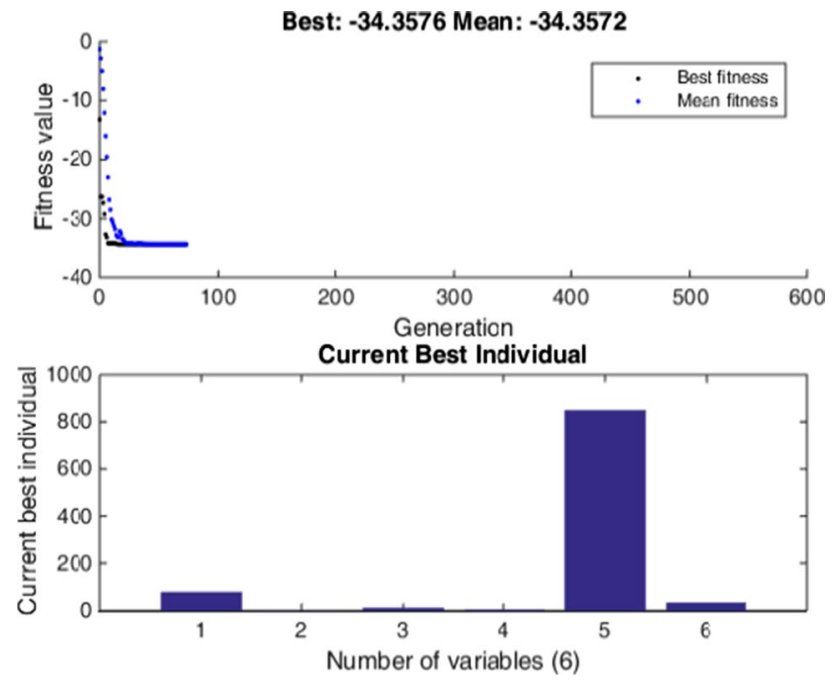

Fig. 8 Current best individual using genetic algorithm

$W_{i}=\frac{V_{i}}{\sum_{i=1}^{n} V_{i}}$

The hybrid weights are computed using the geometric mean of AHP and Equal weights. Each value of the geometric mean is divided by the sum of all geometric values. The objective weights assigned to different response parameters are shown in Table 4.
MATLAB is used to run the genetic algorithm program codes, and the results are summarized in Table 5. The result of multi-objective optimization showed that the value of SG set voltage is constant in all conditions of optimization. The value of Ip, Ton and Toff is also same in all conditions of multi-objective optimization.

It can be concluded that values remain constant for equal weight, AHP weight, objective weight, and hybrid weight functions. Moreover, values for pulse-off time remain constant for all weights while values differ for the two parameters in the case of MRR, SR, and SG weight settings.

Figure 8 shows the best individual value of each parameter for multi-objective optimization using hybrid weights. It can be deduced that a total number of 72 generations were involved when genetic algorithm codes were executed by MATLAB for finding the best results. Moreover, the mean and best fitness values are very close to each other which confirms the accuracy of the results. It is advised that the value of pulse peak current must be set at $80 \mathrm{~A}$, pulse-on-time at $0.5 \mu \mathrm{s}$, pulse-off-time at $12 \mu \mathrm{s}$, wire feed rate at $12 \mathrm{~m} / \mathrm{min}$., wire tension at $850 \mathrm{G}$, spark gap-set voltage at $35 \mathrm{~V}$. The confirmatory experiments (Table 6) were performed at suggested set of parameters, and it was observed that there is an improvement in all the response parameters.

$$
\begin{aligned}
Z_{\mathrm{MIN}}= & -W_{1}(-94+0.53 A-35.1 B+1.74 C+4.9 D+0.148 E+3.98 F-0.00233 A \times A+26.6 B \times B \\
& -0.056 C \times C+0.0999 D \times D-0.000036 E \times E-0.0431 F \times F-0.000486 A \times E-0.0261 A \times F \\
& -0.0324 B \times E+2.28 B \times F+0.00240 C \times E-0.116 C \times F-0.0111 D \times E-0.536 D \times F \\
& +0.00581 A \times D \times F-0.130 B \times D \times F+0.000217 D \times E \times F)+W_{2}(-91.4+0.615 A-5.5 B+2.69 C \\
& +4.14 D+0.0937 E+0.430 F-0.00307 A \times A+3.95 B \times B-0.0828 C \times C+0.0282 D \times D \\
& -0.000024 E \times E-0.0252 F \times F-0.000302 A \times E+0.00892 A \times F-0.01836 B \times E+0.215 B \times F \\
& +0.001266 C \times E-0.0464 C \times F-0.00721 D \times E-0.159 D \times F+0.00043 A \times D \times F+0.0572 B \times D \times F \\
& +0.000161 D \times E \times F+W_{3}(0.088-0.000749 A-0.0247 B-0.00456 C-0.00143 D-0.000067 E \\
& +0.00405 F+0.000006 A \times A+0.0219 B \times B+0.000156 C \times C-0.000083 D \times D+0.000000 E \times E \\
& +0.000006 F \times F+0.000000 A \times E-0.000048 A \times F+0.000026 B \times E+0.00112 B \times F \\
& -0.000003 C \times E+0.000059 C \times F+0.000009 D \times E-0.000263 D \times F+0.000004 A \times D \times F \\
& -0.000267 B \times D \times F-0.000000 D \times E \times F)
\end{aligned}
$$

\subsection{Implementation of Genetic Algorithm (GA)}

GA is a nature-based algorithm and used to solve nonlinear objective functions. Holland [34] developed the GA and further modified by Goldberg [35] in 1989. GA is used to achieve the best fitness values, and its results are more reliable, especially in a constrained optimization problem. The process flowchart of the genetic algorithm is shown in Fig. 7.

\section{Conclusions}

The hybrid aluminum metal matrix composites have been machined using the WEDM process under five different machining conditions, and output is computed in terms of MRR, SG, and SR. It was found that different parameters, i.e., Ip, Ton, Toff, WF, WT, and SV have a conflicting influence on the response which led to the need for the 
Table 6 Comparison of response during confirmatory experiments

\begin{tabular}{llllc}
\hline S. No & Response & $\begin{array}{l}\text { Observed value (Indi- } \\
\text { vidual best) }\end{array}$ & $\begin{array}{l}\text { Observed value (At Opti- } \\
\text { mum conditions) }\end{array}$ & $\begin{array}{l}\text { Percentage } \\
\text { improve- } \\
\text { ment }\end{array}$ \\
\hline 1 & MRR $\left(\mathrm{mm}^{3} / \mathrm{min}\right)$ & 12.212 & 13.897 & 13.79 \\
2 & SR $(\mu \mathrm{m})$ & 1.101 & 0.890 & -19.16 \\
3 & SG $(\mathrm{mm})$ & 0.016 & 0.014 & -12.50 \\
\hline
\end{tabular}

implementation of advanced optimization tools for the selection of optimum parameters. The combined implementation of regression, weighted sum method, AHP, and GA has been performed to identify optimum parametric settings for different objective weights. The manufacturers have the flexibility to adopt suggested combinations of parameters for achieving desired results. The following conclusions are derived from present experimentation:

- The results of multi-objective optimization advised to set the value of Ip at $80 \mathrm{~A}$, Ton at $0.5 \mu \mathrm{s}$, Toff at $12 \mu \mathrm{s}, \mathrm{WF}$ at $5 \mathrm{~m} / \mathrm{min}$, WT at $850 \mathrm{G}$, and SV at $35 \mathrm{~V}$ to get optimum values of response parameters.

- The percentage improvement of $13.79 \%, 19.16 \%$, and $12.50 \%$ has been observed as compared to individual best values during the confirmatory experiments.

Open Access This article is licensed under a Creative Commons Attribution 4.0 International License, which permits use, sharing, adaptation, distribution and reproduction in any medium or format, as long as you give appropriate credit to the original author(s) and the source, provide a link to the Creative Commons licence, and indicate if changes were made. The images or other third party material in this article are included in the article's Creative Commons licence, unless indicated otherwise in a credit line to the material. If material is not included in the article's Creative Commons licence and your intended use is not permitted by statutory regulation or exceeds the permitted use, you will need to obtain permission directly from the copyright holder. To view a copy of this licence, visit http://creativecommons.org/licenses/by/4.0/.

\section{References}

1. Nturanabo, F.; Masu, L.; Kirabira, J.B.: Novel applications of aluminium metal matrix composites. In: Cooke, K. (Ed.) Aluminium Alloys and Composites, pp. 71-94. Intechopen, London (2019)

2. Rajmohan, T.; Palanikumar, K.: Experimental investigation and analysis of thrust force in drilling hybrid metal matrix composites by coated carbide drills. Mater. Manuf. Process. 26(8), 961-968 (2011)

3. Mavhungu, S.T.; Akinlabi, E.T.; Onitiri, M.A.; Varachia, F.M.: Aluminum matrix composites for industrial use: advances and trends. Proced. Manuf. 7, 178-182 (2017)

4. Sharma, D.K.; Mahant, D.; Upadhyay, G.: Manufacturing of metal matrix composites: a state of review. Mater. Today: Proc. 26, 506-519 (2020)

5. Suresha, S.; Sridhara, B.K.: Friction characteristics of aluminium silicon carbide graphite hybrid composites. Mater. Des. 34, 576$583(2012)$
6. Sharma, A.K.; Bhandari, R.; Aherwar, A.; Rimašauskienė, R.; Pinca-Bretotean, C.: A study of advancement in application opportunities of aluminum metal matrix composites. Mater. Today: Proc. 26, 2419-2424 (2020)

7. Heinz, A.; Haszler, A.; Keidel, C.; Moldenhauer, S.; Benedictus, R.; Miller, W.S.: Recent development in aluminium alloys for aerospace applications. Mater. Sci. Eng., A 280(1), 102-107 (2000)

8. Surappa, M.K.: Microstructure evolution during solidification of DRMMCs (Discontinuously reinforced metal matrix composites): state of art. J. Mater. Process. Technol. 63(1-3), 325-333 (1997)

9. Hashim, J.; Looney, L.; Hashmi, M.S.J.: Metal matrix composites: production by the stir casting method. J. Mater. Process. Technol. 92, 1-7 (1999)

10. Ramanathan, A.; Krishnan, P.K.; Muraliraja, R.: A review on the production of metal matrix composites through stir casting-furnace design, properties, challenges, and research opportunities. J. Manuf. Process. 42, 213-245 (2019)

11. Yigezu, B.S.; Jha, P.K.; Mahapatra, M.M.: The key attributes of synthesizing ceramic particulate reinforced Al-based matrix composites through stir casting process: a review. Mater. Manuf. Process. 28(9), 969-979 (2013)

12. Kunieda, M.; Lauwers, B.; Rajurkar, K.P.; Schumacher, B.M.: Advancing EDM through fundamental insight into the process. CIRP Ann. 54(2), 64-87 (2005)

13. Garg, R.K.; Singh, K.K.; Sachdeva, A.; Sharma, V.S.; Ojha, K.; Singh, S.: Review of research work in sinking EDM and WEDM on metal matrix composite materials. Int. J. Adv. Manuf. Technol. 50(5), 611-624 (2010)

14. Yue, T.M.; Dai, V.: Wire electrical discharge machining of $\mathrm{Al} 2 \mathrm{O} 3$ particle and short fibre reinforced aluminium based composites. Mater. Sci. Technol. 12(10), 831-836 (1996)

15. Pramanik, A.; Islam, M.N.; Boswell, B.; Basak, A.K.; Dong, Y.; Littlefair, G.: Accuracy and finish during wire electric discharge machining of metal matrix composites for different reinforcement size and machining conditions. Proc. Inst. Mech. Eng., Part B: J. Eng. Manuf. 232(6), 1068-1078 (2018)

16. Rajyalakshmi, G.; Ramaiah, P.V.: Multiple process parameter optimization of wire electrical discharge machining on Inconel 825 using Taguchi grey relational analysis. Int. J. Adv. Manuf. Technol. 69(5-8), 1249-1262 (2013)

17. Fard, R.K.; Afza, R.A.; Teimouri, R.: Experimental investigation, intelligent modeling and multi-characteristics optimization of dry WEDM process of Al-SiC metal matrix composite. J. Manuf. Process. 15(4), 483-494 (2013)

18. Rao, T.B.; Krishna, A.G.: Simultaneous optimization of multiple performance characteristics in WEDM for machining ZC63/SiCp MMC. Adv Manuf 1(3), 265-275 (2013)

19. Fenghong, C.; Chang, C.; Zhenyu, W.; Muthuramalingam, T.; Anbuchezhiyan, G.: Effects of silicon carbide and tungsten carbide in aluminium metal matrix composites. Silicon 11(6), 26252632 (2019)

20. Palanisamy, D.; Devaraju, A.; Manikandan, N.; Balasubramanian, K.; Arulkirubakaran, D.: Experimental investigation and 
optimization of process parameters in EDM of aluminium metal matrix composites. Mater. Today: Proc. 22, 525-530 (2020)

21. Coyal, A.; Yuvaraj, N.; Butola, R.; Tyagi, L.: An experimental analysis of tensile, hardness and wear properties of aluminium metal matrix composite through stir casting process. SN Appl. Sci. 2(5), 1-10 (2020)

22. Yadav, P.K.; Patel, S.K.; Singh, V.P.; Verma, M.K.; Singh, R.K.; Kuriachen, B.; Dixit, G.: Effect of different reinforced metalmatrix composites on mechanical and fracture behaviour of aluminium piston alloy. J. Bio-and Tribo-Corrosion 7(2), 1-12 (2021)

23. Kar, C.; Surekha, B.: Characterisation of aluminium metal matrix composites reinforced with titanium carbide and red mud. Mater. Res. Innov. 25(2), 67-75 (2021)

24. Manda, C.S.; Babu, B.S.; Ramaniah, N.: Effect of heat treatment on mechanical properties of aluminium metal matrix composite (AA6061/MoS2). Adv. Mater. Process. Technol. (2021). https:// doi.org/10.1080/2374068X.2020.1860593

25. Saravanakumar, A.; Ravikanth, D.; Rajeshkumar, L.; Balaji, D.; Ramesh, M.: Tribological behaviour of MoS2 and graphite reinforced aluminium matrix composites. IOP Conf. Ser. Mater. Sci. Eng. 1059, 012021 (2021)

26. Kumar, M.S.; Begum, S.R.; Pruncu, C.I.; Asl, M.S.: Role of homogeneous distribution of $\mathrm{SiC}$ reinforcement on the characteristics of stir casted Al-SiC composites. J. Alloys Compd. 869, 159250 (2021)

27. Krishnan, P.K.; Arunachalam, R.; Husain, A.; Al-Maharbi, M.: Studies on the influence of stirrer blade design on the microstructure and mechanical properties of a novel aluminum metal matrix composite. J. Manuf. Sci. Eng. 143(2), 021008 (2021)

28. Kumar, M.S.; Pruncu, C.I.; Harikrishnan, P.; Begum, S.R.; Vasumathi, M.: Experimental investigation of in-homogeneity in particle distribution during the processing of metal matrix composites. Silicon (2021). https://doi.org/10.1007/s12633-020-00886-4

29. Faraz, M.; Haseebuddin, M.R.; Pal, B.: Mechanical properties of aluminum metal matrix composite reinforced with silicon carbide using FEM. IOP Conf. Ser. Mater. Sci. Eng. 1013, 012013 (2021)

30. Kumar, A.; Grover, N.; Manna, A.; Chohan, J.S.; Kumar, R.; Singh, S.; Pruncu, C.I.: Investigating the influence of WEDM process parameters in machining of hybrid aluminum composites. Adv. Compos. Lett. 29, 2633366X2096313 (2020)

31. Kumari, K.; Yadav, S.: Linear regression analysis study. Journal of the Practice of Cardiovascular Sciences 4(1), 33 (2018)

32. Rao, R.V.; Patel, B.K.: A subjective and objective integrated multiple attribute decision making method for material selection. Mater. Des. 31(10), 4738-4747 (2010)

33. Saaty, T.L.: The Analytic Hierarchy Process. McGraw-Hill, New York (1980)

34. Holland, J.H.: Adaptation in Natural and Artificial Systems. University of Michigan Press, Michigan (1975)

35. Goldberg, D.E.: Genetic Algorithms in Search Optimization and Machine Learning. Addison Wesley, Massachusetts (1989) 